\title{
Limited joint mobility in diabetes mellitus
}

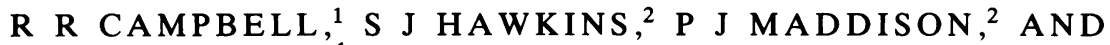 \\ J P D RECKLESS ${ }^{1}$
}

From the ${ }^{1}$ Royal United Hospital, Bath, and the ${ }^{2}$ Royal National Hospital for Rheumatic Diseases, Bath

SUMMARY The relationship of limited joint mobility and finger joint contractures in diabetics to age of onset, duration, and control of diabetes has not been established. We measured the mobility of metacarpophalangeal, wrist, elbow, and ankle joints and assessed the prevalence of finger joint contractures in 254 young diabetics and 110 controls. The presence of microvascular disease was assessed by ophthalmoscopy and urine analysis for proteinuria. An estimate of longterm diabetic control was obtained from a postal questionnaire. A generalised reduction in joint mobility was present in diabetics of all ages two years after diagnosis. The reduction in joint mobility in controls between the ages of 12 and 13 was exaggerated in the diabetics. Diabetics diagnosed before puberty were more severely affected than those with a postpubertal onset, independent of duration of diabetes. Finger joint contractures were a significant feature of longstanding diabetics (nine years or more duration) only.

Key words: microvascular disease, glycosylation, collagen.

Stiffness of the hands associated with increased skin thickness was reported in five adult diabetics in 1957. ${ }^{1}$ This phenomenon was redescribed by Rosenbloom and Frias in $197 \overline{4}^{2}$ and confirmed by larger studies of insulin-dependent diabetic children. ${ }^{3-5}$ The term cheiroarthropathy (cheiro $=$ hand) indicates that the hand abnormalities are the most striking, but larger joints can also be involved, and 'limited joint mobility' has been suggested as a more appropriate title.

The overall prevalence of joint contractures in these studies varied from 9 to $32 \%$, reflecting the variability of the samples studied and of the screening methods used. The relative influences of age, duration of diabetes, and the importance of diabetic control have yet to be established. Clinical interest lies particularly in the suggestion that limited joint mobility could act as a marker for microvascular complications in longstanding diabetics. ${ }^{5}$

This study examines ranges of joint mobility and the prevalance of hand contractures in diabetic and control groups, and relates these findings to duration of diabetes, age at onset, the quality of diabetic control, and the presence of microvascular disease.

Accepted for publication 5 June 1984.

Correspondence to Dr R R Campbell, Royal United Hospital, Combe Park, Bath.

\section{Subjects and methods}

Two hundred and fifty-four insulin-dependent diabetics aged 6 to 39 were studied (143 males, 111 females), along with 110 similarly-aged controls (54 males, 56 females). Two hundred and twenty-three of the diabetics were examined at the British Diabetic Association's (BDA) summer holiday camps for children and the other 31 were seen in diabetic outpatient clinics. All of the 223 children at the holiday camps were regular attenders at outpatient clinics and represented a broad spectrum of childhood and adolescent diabetes in terms of duration, severity, and control. The control group was made up of volunteer healthy schoolchildren and hospital staff members.

Details of age and duration of diabetes were recorded. The quality of long-term diabetic control was assessed by reviewing outpatient clinic notes or, for the children at the BDA summer camps, by replies to a postal questionnaire sent to consultant paediatricians. The response rate to the questionnaire was $70 \%$. Long-term diabetic control was graded according to the mean clinic blood glucose over the previous four years as good (mean glucose 3-10 mmol/l (54-180 mg/dl)), fair (10.1-14 mmol/l $(181-252 \mathrm{mg} / \mathrm{dl})$ ) or poor (greater than $14 \mathrm{mmol} / \mathrm{l}$ $(252 \mathrm{mg} / \mathrm{dl}))$. 
Finger joint contractures were detected by a table top test for fixed flexion deformities of the proximal interphalangeal (PIP) joints, in which the entire palmar surfaces of all fingers must be in contact with the table top to be recorded as a pass (Fig. 1). Fixed flexion deformity of the little finger alone was regarded as a normal variant and not counted as

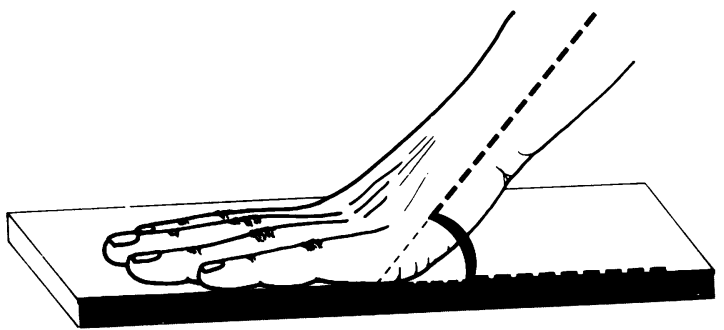

Fig. 1 Method of measuring metacarpophalangeal joint extension.

Table 1 Values for the calculation of overall joint mobility score

\begin{tabular}{|c|c|c|c|}
\hline & 0 & 1 & 2 \\
\hline MCP extension & $<45^{\circ}$ & $45-60^{\circ}$ & $>60^{\circ}$ \\
\hline Wrist range & $<155^{\circ}$ & $155-180^{\circ}$ & $>180^{\circ}$ \\
\hline Elbow extension & $\begin{array}{l}\text { Fixed } \\
\quad \text { flexion }\end{array}$ & $\begin{array}{l}\text { Full } \\
\quad \text { extension }\end{array}$ & Hyperextension \\
\hline Ankle range & $<60^{\circ}$ & $60-80^{\circ}$ & $>80^{\circ}$ \\
\hline Table top screen & Bad fail* & Fail & Pass \\
\hline
\end{tabular}

*More than $20^{\circ}$ fixed flexion in two fingers or more. failure. Metacarpophalangeal (MCP) joint exten $\frac{}{3}$ sion was measured by asking the subject to lift the믄 hand as far as possible off the table while the fingers. were held flat on the table by the examiner, so that all four finger MCP joints were fully extende 6 together. The angle between the midline of the्c ulnar border of the hand and the table top wasn recorded. The ranges of full passive movements for both wrists and both ankles and the angle of fulfo elbow extension were measured by goniometry. These procedures yielded a total of five join $\overrightarrow{0}$ measurements for analysis: wrist range, ankle range $\vec{\overrightarrow{ }}$ MCP extension angle, elbow extension (graded a fixed flexion, straight, or hyperextension) and thom screening for hand contractures (pass or fail). The mean of the values for right and left was taken tof give a single average value for each joint measured

A scoring system was devised for an overal assessment of joint mobility (Table 1). A score of 2 was allotted to each normal joint, 1 for eachequivocal result, and 0 for a definite abnormality giving a maximum total score of 10 for the five join? measurements.

The presence of microangiopathy was assessed by ophthalmoscopy and by testing of the urine foro proteinuria (Albustix), $1+$ or more being positifẹ

\section{Results}

No differences between males and females were found for any of the measurements, and the result for both sexes were pooled for subsequent analysis?

Table 2 Relationship of limited joint mobility to age (statistical analysis by unpaired Student's test for wrist, ankle and $M C P ; \chi^{2}$ test for elbow extension; Fisher's exact probability test for finger joint contractures and elbow extension 19-39-year olds)

\begin{tabular}{|c|c|c|c|c|c|c|c|c|c|}
\hline & $\begin{array}{l}\text { Controls } \\
\text { Diabetics }\end{array}$ & $\begin{array}{l}6-10 \text {-year } \\
n=27 \\
n=129\end{array}$ & olds & $\begin{array}{l}11-13 \text {-year } \\
n=30 \\
n=68\end{array}$ & olds & $\begin{array}{l}\text { 14-18-year } \\
n=26 \\
n=26\end{array}$ & olds & $\begin{array}{l}\text { 19-39-year } \\
n=27 \\
n=31\end{array}$ & olds \\
\hline $\begin{array}{l}\text { Mean wrist } \\
\text { range }\end{array}$ & $\begin{array}{l}\text { Controls } \\
\text { Diabetics }\end{array}$ & $\begin{array}{l}180^{\circ} \pm 17 \\
162^{\circ} \pm 14^{*}\end{array}$ & & $\begin{array}{l}174^{\circ} \pm 15 \\
161^{\circ} \pm 17^{*}\end{array}$ & & $\begin{array}{l}172^{\circ} \pm 12 \\
135^{\circ} \pm 20^{*}\end{array}$ & & $\begin{array}{l}168^{\circ} \pm 13 \\
152^{\circ} \pm 15^{*}\end{array}$ & \\
\hline $\begin{array}{l}\text { Mean ankle } \\
\text { range }\end{array}$ & $\begin{array}{l}\text { Controls } \\
\text { Diabetics }\end{array}$ & $\begin{array}{l}75^{\circ} \pm 13^{\dagger} \\
69^{\circ} \pm 13\end{array}$ & & $\begin{array}{l}75^{\circ} \pm 12^{\dagger} \\
67^{\circ} \pm 11\end{array}$ & & $\begin{array}{l}70^{\circ} \pm 10 \\
48^{\circ} \pm 14^{*}\end{array}$ & & $\begin{array}{l}72^{\circ} \pm 12 \ddagger \\
66^{\circ} \pm 10\end{array}$ & \\
\hline $\begin{array}{r}\text { Mean MCP } \\
\text { extension }\end{array}$ & $\begin{array}{l}\text { Controls } \\
\text { Diabetics }\end{array}$ & $\begin{array}{l}70^{\circ} \pm 12_{\ddagger} \\
65^{\circ} \pm 13\end{array}$ & & $\begin{array}{l}69^{\circ} \pm 9 \\
62^{\circ} \pm 13^{*}\end{array}$ & & $\begin{array}{l}59^{\circ} \pm 12 \\
47^{\circ} \pm 10^{*}\end{array}$ & & $\begin{array}{l}58^{\circ} \pm 10 \\
47^{\circ} \pm 13^{*}\end{array}$ & \\
\hline $\begin{array}{l}\text { Mean elbow } \\
\text { extension }\end{array}$ & $\begin{array}{l}\text { Controls } \\
\text { Diabetics }\end{array}$ & $\begin{array}{l}\text { No hyper- } \\
\text { extension } \\
6 \\
58\end{array}$ & $\begin{array}{l}\text { Hyper- } \\
\text { extension } \\
21_{\ddagger} \\
71\end{array}$ & $\begin{array}{l}\text { No hyper- } \\
\text { extension } \\
18 \\
42\end{array}$ & $\begin{array}{l}\text { Hyper- } \\
\text { extension } \\
12 \text { NS } \\
26\end{array}$ & $\begin{array}{l}\text { No hyper- } \\
\text { extension } \\
9 \\
19\end{array}$ & $\begin{array}{l}\text { Hyper- } \\
\text { extension } \\
17 \\
7^{*}\end{array}$ & $\begin{array}{l}\text { No hyper- } \\
\text { extension } \\
12 \\
27\end{array}$ & $\begin{array}{l}\text { Hyper- } \\
\text { extension } \\
15 \\
4^{*}\end{array}$ \\
\hline $\begin{array}{l}\text { Finger joint } \\
\text { contractures }\end{array}$ & $\begin{array}{l}\text { Controls } \\
\text { Diabetics } \\
\text { Exact probability }\end{array}$ & $\begin{array}{l}\text { Pass } \\
27 \\
121 \\
\quad \mathrm{p}=0.21\end{array}$ & $\begin{array}{c}\text { Fail } \\
0 \\
8\end{array}$ & $\begin{array}{l}\text { Pass } \\
29 \\
57 \\
\quad p=0.057\end{array}$ & $\begin{array}{c}\text { Fail } \\
1 \\
11\end{array}$ & $\begin{array}{l}\text { Pass } \\
24 \\
17 \\
\quad p=0.017\end{array}$ & $\begin{array}{c}\text { Fail } \\
2 \\
9\end{array}$ & $\begin{array}{l}\text { Pass } \\
26 \\
22 \\
\quad p=0.01\end{array}$ & $\begin{array}{c}\text { Fail } \\
1 \\
9\end{array}$ \\
\hline
\end{tabular}


The effect of age on joint mobility is shown in Table 2 . The age groupings have been chosen to represent children before the pubertal growth spurt (6-10 years old), an approximately peripubertal group (11-13 years old), and subjects after the growth spurt (14-39). Highly significant reductions in joint mobility were found in diabetics compared with controls in every age group.

Fig. 2 shows the overall joint mobility scores for controls and diabetics related to age. In the control group a gradual reduction is seen with increasing age, but with a sharp decline between the ages of 12
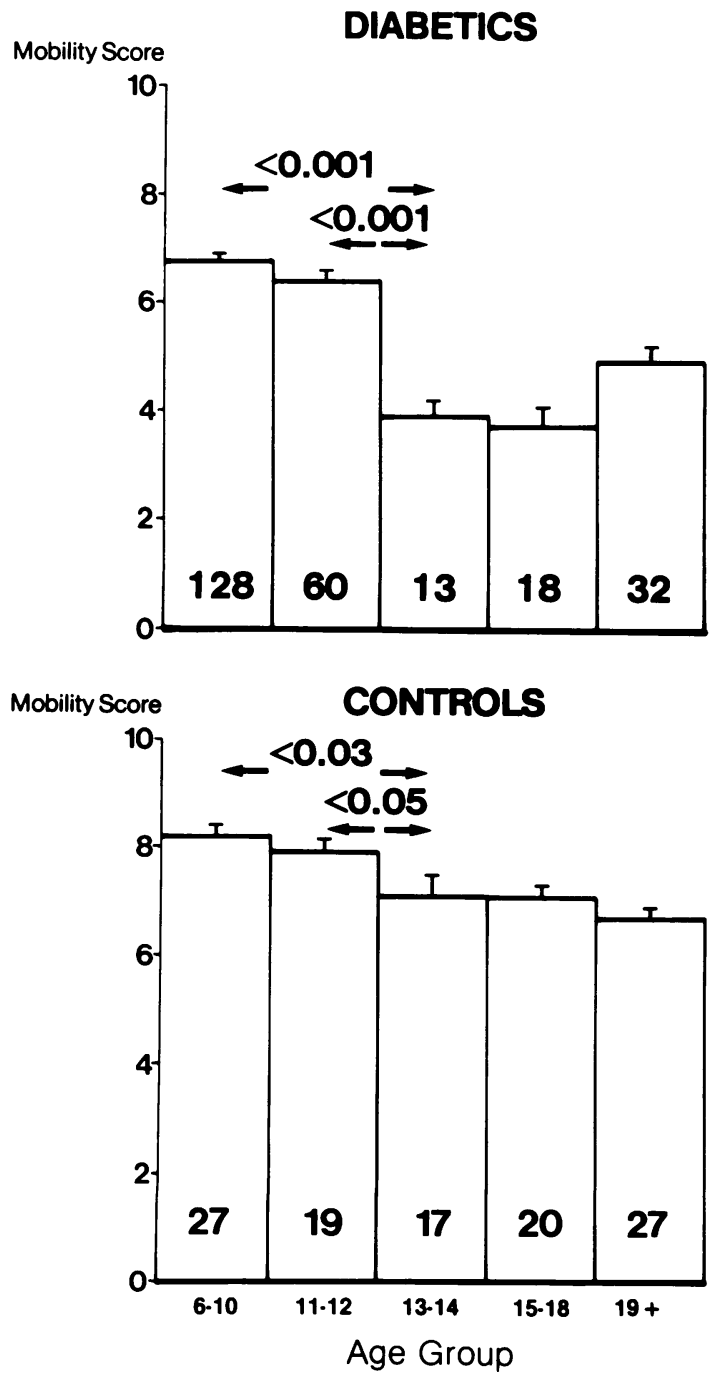

Fig. 2 Change in overall joint mobility score with increasing age (histogram represents means $+S E M s$; statistical analysis by Mann-Whitney $U$ test). and $13(p<0.05$, Mann-Whitney $U$ test $)$. This decline was considerably exaggerated in the diabetic population $(\mathrm{p}<0.001$, Mann-Whitney $U$ test, for diabetics 11-12 years versus 13-14 years). On the basis of this significant change around puberty subjects were divided into two groups aged 6-12 (prepubertal) and 13-39 (postpubertal) to simplify further analysis.

Fig. 3 illustrates the effect of duration of diabetes on joint mobility. Significant reductions in mobility were apparent in diabetics two years from diagnosis as compared with controls. In the 6-12-year old diabetics, where the number of recently diagnosed diabetics is sufficiently large to enable comparison, joint mobility was significantly reduced one year after diagnosis $(\mathrm{p}<0 \cdot 005$, Mann-Whitney $U$ test $)$. Although no further sudden changes in joint mobility were seen, there was a gradual deterioration with increasing disease duration, so that diabetics of nine years' or more duration were significantly worse than those of two years' duration or less.

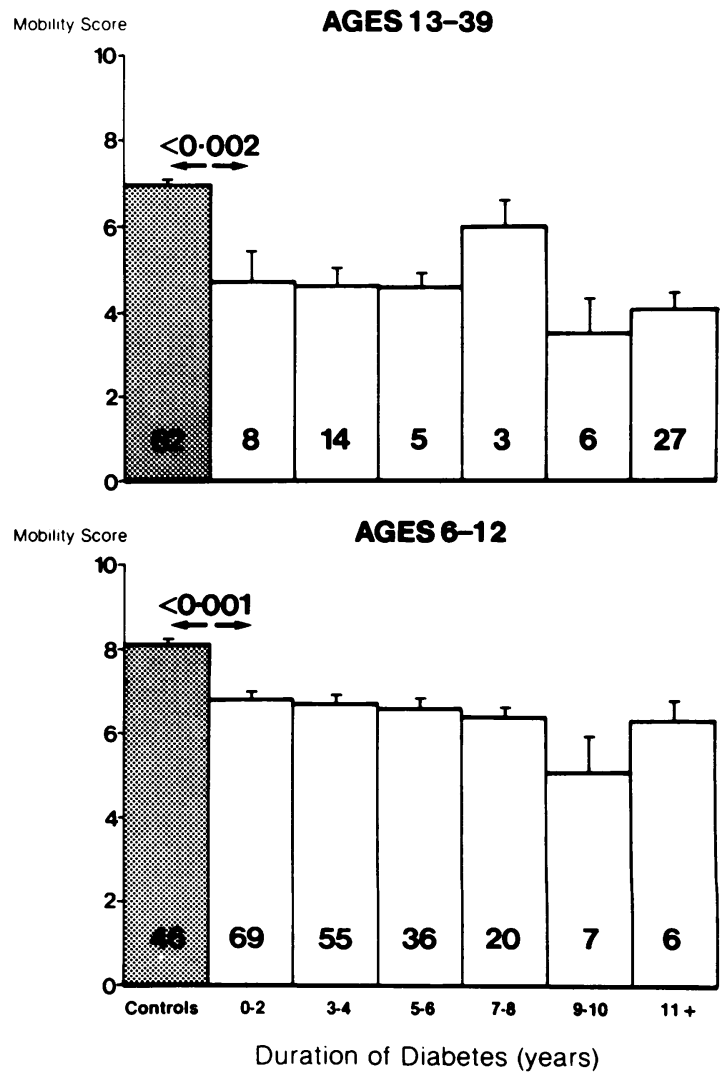

Fig. 3 Effect of duration of diabetes on overall joint mobility scores (histogram represents means $+S E M s$; statistical analysis by Mann-Whitney $U$ test). 
Finger joint contractures were present in 19 out of 44 longstanding diabetics of nine years' or more duration, a significant increase over both controls (4 out of 110 , Fisher's exact probability $=7.6 \times 10^{-7}$ ) and diabetics of less than nine years' duration (20 out of $\left.210, \chi^{2}=31 \cdot 7, p<0 \cdot 0001\right)$.

In Fig. 4 the effect of age of onset is examined in groups of diabetics with a similar disease duration. Both in patients with a short duration of diabetes (eight years or less) and in those of long duration (nine years plus), individuals with an early onset of diabetes had decreased joint mobility as compared with later onset diabetics (onset 13 years plus). Although the diabetics with onset later than 12 years old had less reduction in joint mobility than those with an early onset, their mobility score $(3 \cdot 7 \pm 1 \cdot 8$ (=mean \pm standard deviation)) was still less than in similarly aged controls $(7 \cdot 0 \pm 1 \cdot 3, p<0 \cdot 001$, Wilcoxon's signed rank).

The quality of diabetic control also appeared to influence joint mobility. In the 6-12 year olds poorly controlled diabetics (mean score 6.3 $41 \cdot 6$ ) were significantly worse than both the moderately controlled group $(6.9 \pm 1.4, p<0.05$, Mann-Whitney $U$ test) and the good control group $(7 \cdot 0 \pm 1 \cdot 5, p<0 \cdot 05$, Mann-Whitney $U$ test). Ages of onset and disease duration were similar in all three groups. A similar trend was apparent in the 13-39 year old diabetics (good control group $3.9 \pm 2 \cdot 7$, moderate group

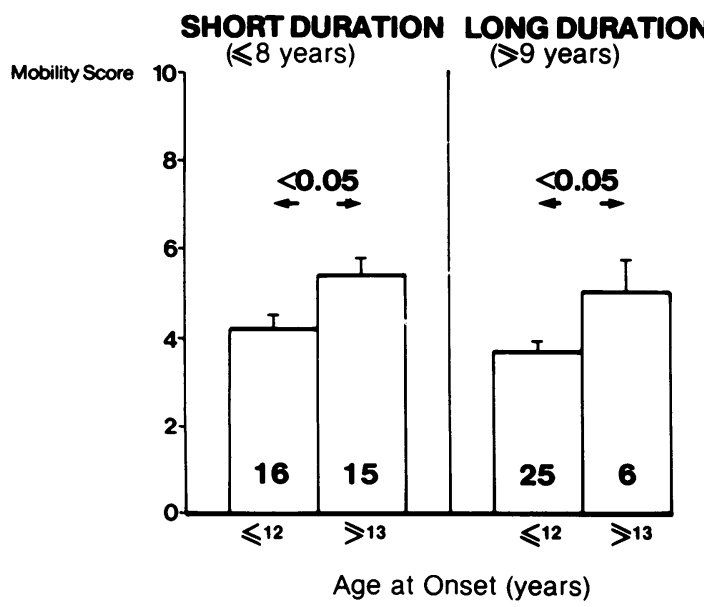

Fig. 4 Effect of age of onset of diabetes, prepubertal $(<12$ years old) and postpubertal ( $>13$ years old), on overall joint mobility scores. To exclude effects of age and duration of diabetes only diabetics aged 13-39 are represented and are divided into groups of similar duration: on the left those with a duration of eight years or less and on the right those with a disease duration of nine years or more. (Statistical analysis by Wilcoxon's signed rank).
$3 \cdot 7 \pm 1 \cdot 8$, poor group $3 \cdot 4 \pm 2 \cdot 3$ ), but the differences were not statistically significant.

The incidence of clinically obvious microvascular $\stackrel{?}{?}$ disease was low: there were only three cases of $\overrightarrow{\bar{S}}$ retinopathy seen and one of proteinuria, so that nomeaningful comparison of joint mobility and micro- $\frac{\bar{O}}{0}$ vascular disease could be made.

\section{Discussion}

This study has shown that joint mobility is reduced $\vec{\theta}$ in insulin-dependent diabetics of all ages compared with similarly aged controls. A general but asymp- $\vec{\omega}$ tomatic reduction in joint mobility is established two years after diagnosis. There is continuing gradual $\bar{\alpha}$ deterioration with increasing duration of disease, $A$ though finger joint contractures are prevalent only $\dot{\sim}$ in longstanding diabetics with a disease duration of $\underset{\omega}{\omega}$ nine years or more.

The rapidity with which the generalised, asymptomatic reduction in joint mobility becomes appa- $\vec{T}$ rent after diagnosis suggests that the process $\frac{\mathbb{O}}{-}$ responsible begins within months of the onset of hyperglycaemia. Recent experimental work has demonstrated that non-enzymatic glycosylation of $\overrightarrow{0}$ collagens is markedly accelerated in diabetics arof results in abnormally cross-linked collagens whieh are unusually resistant to mechanical and enzymati degradation. $^{6-8}$ In-vitro experimental work hă shown that, in animal collagen incubated in an $\overline{0}$ extreme hyperglycaemic environment, accelerated $\stackrel{0}{\circ}$ non-enzymatic glycosylation is biochemically detect- $\stackrel{\mathbb{Q}}{2}$ able within 10 days, ${ }^{9}$ but at levels of hyperglycaemia $\overrightarrow{\vec{O}}$ occurring in vivo the process is likely to take 3 considerably longer, probably several months, to become clinically important. The time scale of these? events may well provide an explanation for the asymptomatic reduction in joint mobility over a? period of months observed in this study, and is in $\frac{5}{3}$ accord with previous work linking limited joint mobility and the non-enzymatic glycosylation of collagens. ${ }^{10}$

The lower overall joint mobility observed in 의 poorly-controlled diabetics provides further evi- $\frac{D}{O}$ dence that hyperglycaemia per se is important in the generation of reduced joint mobility. Indeed there is $\tilde{\sigma}$ an anecdotal report of skin thickness being successfully reduced in three diabetics controlled by an insulin infusion pump, ${ }^{11}$ raising the possibility that $\omega$ rigorous control of diabetes may be capable of preventing, or even reversing, the skin changes. 0

Limitation of joint mobility was more marked in diabetics with a prepubertal onset than in those ${ }^{?}$ diagnosed after puberty. Furthermore, reduction in ${ }^{\circ}$ joint mobility seen between the ages of 12 and 13 in $\frac{\text { Pे }}{\bar{D}}$ the control group was considerably accentuated in 
the diabetics. It has been suggested that hyperglycaemia at puberty might result in the laying down of large amounts of highly-glycosylated collagens during the pubertal growth spurt, ${ }^{12}$ so that individuals who develop diabetes before puberty may be subject to greater reduction of joint mobility.

The occurrence of hand contractures is probably multifactorial. Among the possible aetiological factors said to be more common in diabetics are: peripheral neuropathy with muscle contractures, ${ }^{13}$ Dupuytren's contracture,${ }^{14}$ abnormalities of fibroblast proliferation and function, ${ }^{15}$ microangiopathy, and non-enzymatic glycosylation of collagens. ${ }^{10}$ In this study hand contractures were a significant feature of longstanding diabetics only and were often symptomatic, in contrast to the early, asymptomatic, generalised reduction in joint mobility. Previous studies have shown a close relationship between the presence of hand contractures and the risk of microangiopathy in longstanding diabetics. ${ }^{5}$ In this respect it is interesting to note the similarities between the skin changes of scleroderma and diabetic cheiroarthropathy which have been previously commented upon. ${ }^{16}$ It has been suggested that microangiopathy in a number of different settings, including diabetes mellitus, scleroderma, and lipodermatosclerosis, may eventually lead to similar secondary fibrotic changes in the affected skin, ${ }^{17}$ whatever the underlying pathology. If so, then this could explain the high prevalence of hand contractures in longstanding diabetics and the close link with microvascular complications. Although we made no formal assessment of skin thickness, it was our subjective impression that, in those diabetics with hand contractures, the skin of the hands was thickened and coarser than normal.

Finally, our development of an overall scoring system for joint mobility which shows clear differences between diabetics and normals should enable more accurate serial assessments to be made in future longitudinal studies, which are necessary to establish the predictive value of a falling joint score with reference to the development of diabetic microangiopathy.

\section{References}

1 Lundbaek K. Stiff hands in long-term diabetes. Acta Med Scand 1957; 158: 447-51.

2 Rosenbloom A L, Frias J L. Diabetes mellitus, short stature and joint stiffness - a new syndrome. Clin Res 1974; 22: 92A.

3 Grgic A, Rosenbloom A L, Weber F T, Giordano B, Malone J I, Schuster J J. Joint contracture - common manifestation of childhood diabetes mellitus. J Pediatr 1976; 88: 584-8.

4 Benedetti A, Noacco C, Macor S, Pittaro I. Joint lesions in diabetes. $N$ Engl J Med 1975; 292: 1033-4.

5 Rosenbloom A L. Silverstein J H, Lezotte D C, Richardson K, McCallum M. Limited joint mobility in childhood diabetes mellitus indicates risk for microvascular disease. $N$ Engl J Med 1981; 305: 191-4.

6 Bailey A J. The nonenzymatic glycosylation of proteins. Horm Metab Res 1981; suppl II: 90-4.

7 Chang K, Uitto J, Rowold E A, Grant G A, Kilo C, Williamson $\mathbf{J} \mathbf{R}$. Increased collagen cross-linkages in experimental diabetes. Diabetes 1980; 29: 778-81.

8 Schnider S L, Kohn R R. Effects of age and diabetes mellitus on the solubility and nonenzymatic glycosylation of human skin collagen. J Clin Invest 1981; 67: 1630-5.

9 Guitton J D, Le Pape A, Sizaret P Y, Muh J P. Effects of in vitro $\mathrm{N}$-glucosylation on type-I collagen fibrillogenesis. Biosci Rep 1981; 1: 945-54

10 Buckingham B A, Uitto J, Sandborg C, Keens T, Kaufman F, Landing B. Scleroderma-like syndrome and the non-enzymatic glycosylation of collagen in children with poorly controlled insulin dependent diabetes. Pediatr Res 1981; 15: 626.

11 Lieberman L S, Rosenbloom A L, Riley W J, Silverstein J H. Reduced skin thickness with pump administration of insulin. $N$ Engl J Med 1980; 303: 940-1.

12 Kohn R R, Schnider S L. Glycosylation of human collagen. Diabetes 1982; 31 (suppl 3): 47-51.

13 Jung Y, Hohmann T C, Gerneth J A, et al. Diabetic hand syndrome. Metabolism 1971; 20: 1008-14.

14 Heathcote J G, Cohen H, Noble J. Dupuytren's disease and diabetes mellitus. Lancet 1981; i: 1420.

15 Rowe D W, Starman B J, Fujimoto W Y, Williams R H. Abnormalities in proliferation and protein synthesis in skin fibroblast cultures from patients with diabetes mellitus. Diabetes 1977; 26: 284-90.

16 Seibold J R. Digital sclerosis in children with insulin-dependent diabetes mellitus. Arthritis Rheum 1982; 25: 1357-61.

17 Jayson M I V. Systemic sclerosis - a microvascular disorder? J $R$ Soc Med 1983; 76: 635-42. 